\title{
Mechanical Engineering Product Value Design Applying the Value Engineering Method
}

\author{
Maria Prilutskaya ${ }^{1}$, Anastasia Murukina ${ }^{1,{ }^{*}}$, and Tatiana Dashkova ${ }^{1}$ \\ ${ }^{1}$ Ural Federal University named after the first President of Russia B.N. Yeltsin, Institute of New \\ Materials and Technologies, 620002 Ekaterinburg Mira 19, Russia
}

\begin{abstract}
Today mechanical engineering is one of the most dynamically developing industries. The products of this industry are becoming more and more complex, requiring the continuous introduction of new high technologies into the production process. In addition, the change in the preferences of consumers of mechanical engineering products associated with an increase in the degree of automation and robotization of their production processes leads to the need to apply more flexible product design approaches. These approaches should allow the manufacturer to respond quickly to changing customer needs. Thus, machine-building enterprises need to provide not only the best price-quality ratio, but also to offer a unique set of product functions - a concept that satisfies all the needs of target consumers. In other words, the ability to create product value based on the individual needs of customers is a competitive advantage for a company in the struggle for market share. The application of Value Engineering Method is able to solve these problems.
\end{abstract}

\section{Introduction}

In a highly competitive market environment, the work of modern mechanical engineering enterprises requires not only to constantly improve their products, but also to develop new types of them [1]. Manufacturers receive ideas for new products and new concepts of manufactured products from both external and internal sources, whose representatives can be stakeholders in product development:

- external sources

- customers;

- suppliers;

- competitors;

- patent search;

- research centers and universities;

- associations, industrial exhibitions.

- internal sources

- developers;

- technologists;

\footnotetext{
*Corresponding author: admurukina@urfu.ru
} 
- $\quad$ roduction workers;

- mangers;

- $\quad$ sales representatives, distributors.

Given that, all stakeholders have their own interest in the product and its life cycle, when creating a concept for a new product, it is necessary to determine the impact of the product on each of them. Along with this, different stakeholders can take advantage and benefit from some characteristics or some functions of the product and its life cycle. In the meaning of utility, it is a tangible value or value of use, in the meaning of perception or emotion, it is an intangible value or value of estimation [2].

This article proposes an approach to the design of the value of modern mechanical engineering products using the method of Value Engineering (VE). As an example, we consider the product "electric forklift" of one of the Russian enterprises of lifting and transport engineering. The functional shape of handling equipment becomes more complicated every year, acquiring an extensive multi-level structure. This change is due to the fact that consumers need to automate an increasing number of warehouse operations, in connection with which the equipment should be able to carry out logistics operations with the least human involvement. In addition, each consumer has individual operating conditions that determine the need to select optional parameters for the basic configuration of the product for the most efficient operation of handling equipment. Thus, manufacturers are faced with the task of developing an individual product with the best price-quality ratio. To put this into practice can only be helped by special complex tools that allow you to design a new value taking into account cost restrictions.

\section{Research method}

The method that examines the price-quality ratio is called "Value Analysis" (VA). Application of this method at the stage of product design is called "Value Engineering" (VE). The object of research for the VA is a product introduced to the market or a service already provided, or a process used. The object of research of the VE is a product, process and service at the design stage, their creation. The main principle of the VE is to create product value for the consumer with the lowest or optimal production costs. This method allows clarifying the functional requirements for a new product, building a functional model of the product, comparing functions with the structural element model, excluding unnecessary functions and finding sources of unnecessary costs.

It should be noted that the term "value" is different from the concepts of "price" or "cost", it is the relationship between the function necessary to meet the needs of the consumer and the cost of this function. If "cost" is the cost of producing and selling a product, then "value" is the perception of a product by a specific consumer. Value can be correlated with quality, performance, design and other product characteristics. There are many different types of value [2-4] (figure 1). Despite this, "product perception" is the leading one.

The value perceived by the customer can be represented by the ratio: "perceiving the benefit" / "perceiving the victim" [2]. To develop a demanded product and increase the competitiveness of an enterprise in the market, it is especially important to understand how consumers perceive and evaluate a product (perceiving a benefit) and how much they ready to pay for it (a perceived sacrifice). One of the ways to understand the requirements of users for a product is to study their specific functional and emotional needs, which will ensure their further transformation into specifications and functionality of the product. All this will allow the manufacturer to form various concepts of the same product, to offer the most suitable solution to the customer. In addition, the VE method helps to determine not only the requirements for the product being developed, but also to establish the relationship between the satisfaction of needs and the resources spent on this. The objectively determined product 
value plays a vital role if we want to make the product interesting for the customer or consumer, if we want to meet his expectations [5].
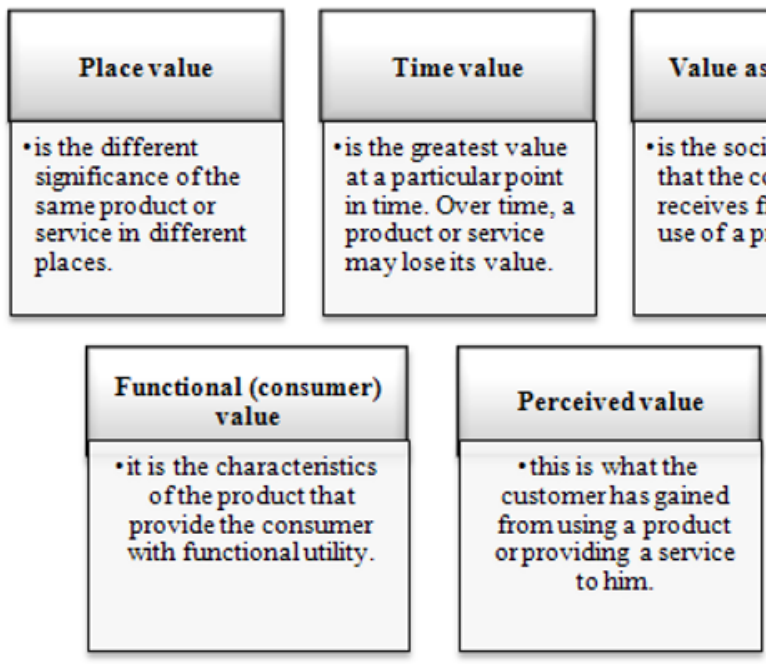
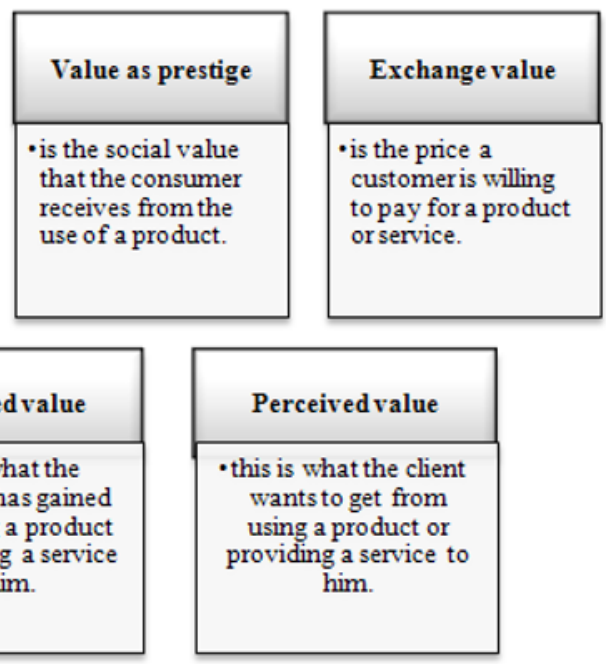

Fig. 1. Value types.

Thus, value is the ratio of product characteristics to their cost.

$$
\text { Value }=\text { Product characteristics } / \text { Cost }
$$

If the numerator increases but the denominator stays the same, the value increases. Product performance can be improved by increasing reliability, safety, maintainability, etc., at the same cost, or by reducing cost at the same degree of the above indicators. In this case, as a result of Value Engineering, the product will perform more functions at the same cost, or the same functions will be performed at lower costs. In other words, VE is a method of increasing the product value while reducing or maintaining its value. The implementation of the VE method can be represented in the form of six sequential steps (figure 2).

When using VE, the first step is to create and then increase the "value" of a product or service by defining its functions and working with it. The same is done with the constituent components and their associated costs. The functions composition is determined by the requirements and preferences of consumers in a particular market segment and can vary significantly from simpler requirements to the most specific. For this it is necessary to conduct a technical characteristics analysis (define a set of primary and secondary functions related to the product's purpose function), as well as a functional needs analysis (define a set of secondary functions related with application or evaluation functions).

Note that all the functions responsible for the technical characteristics of the product will form the basic configuration of the product, while the secondary functions will be included in it only partly. Most of these functions will constitute an optional functional set, which will allow the manufacturer to meet the individual needs of each customer, due to operation features, type of activity, etc. Thus, when forming a functional model of a product, the properties of the product that reflect its functions are determined. Product properties are what the consumer or user, or any other interested party sees in the product to meet their needs. However, some properties of the product are beneficial, while others are disadvantages for the same person. Product properties-advantages such as reliability, durability, design, color, sound and many others, depending on the situation, can turn from an advantage to a disadvantage, for example, the sound becomes loud noise [4]. Product use level expressed in 
terms of its set of "useful properties", can affect the economic or perceived value of the overall product.

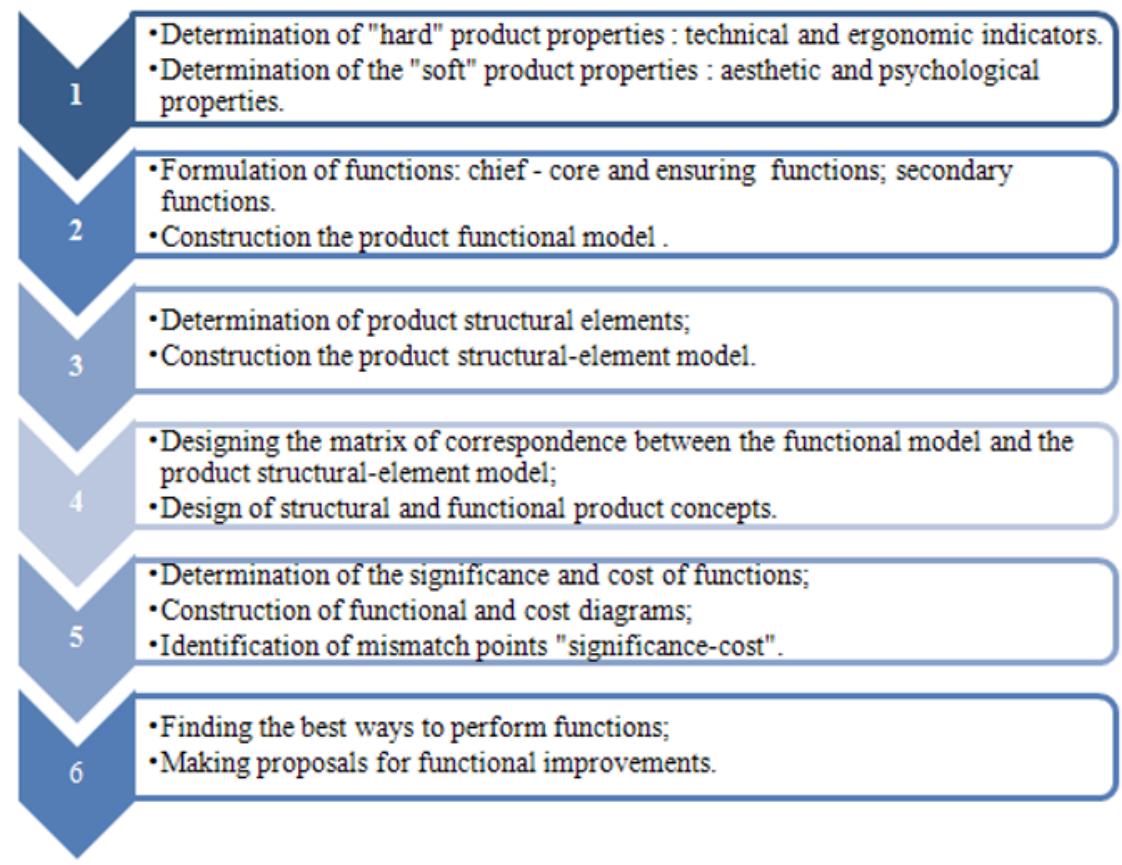

Fig. 2. Value Engineering Method.

From the above, we can conclude that in the VE method, in particular, when constructing a functional model of a product and functional-cost diagrams to identify points of mismatch, it is necessary to take into account the requirements for the developed product of all stakeholders who have an interest in this product and its life cycle. These stakeholders can be consumers of the product, service specialists, designers and technologists of the enterprise where the product is being developed. When determining the significance of each individual product function being developed by an expert method, the opinion of all stakeholders, and not just consumers, as in the traditional VA, should be taken into account. This will allow the formation of objective value, and the VE applying will develop the product by improving quality, reliability, maintainability and other characteristics at the same cost or by reducing the cost while maintaining value. As a result, the product will perform more functions at the same cost, or the same functions will be performed at less cost.

\section{Results}

The authors of this article carried out the Value Engineering of the electric forklift, which allows loading and unloading operations both inside the warehouse complex and outside it. The first step was to define the properties of the designed forklift, which can be divided into the following categories:

- characteristics of the purpose (technical parameters such as lifting capacity, lifting height, etc.);

- maintenance of equipment;

- maintainability;

- possibility of integration into the information system of the warehouse complex;

- ergonomics; 
- safety;

- aesthetics;

- brand.

Then, functions were formulated in accordance with the classification developed by the authors for high-tech products of lifting and transport engineering, which have a complex management structure: operator-driver, internal software and an external system into which the object will be integrated [6]. This classification has the following structure:

- Chief

- Secondary

- Core

- Ensuring

- subsidiary

- managing

- $\quad$ subsidiary

- managing

- $\quad$ ergonomic

- aesthetic

- ecological

- safety

- external system integration

The next step was to form a structural-element model, which included 7 main elements of the forklift:

- lifting mechanism;

- electrical equipment;

- supply system;

- chassis;

- frame;

- body;

- control system.

After that, a matrix of correspondence between the functional model and the structuralelement model of the product was built. Several structural and functional concepts of an electric forklift were proposed, in one of which 39 out of 73 of all secondary functions of the designed product were included in the basic package and 34 functions were attributed to additional options.

The next task was to determine the product elements cost in the context of the structuralelement model, transfer of costs from structural elements to functions and evaluation the compliance of the significance and product functions cost. The calculation of the cost of performing functions consisted in determining the costs of manufacturing material carriers (elements) that implement the corresponding function. The next step is expertly determined the degree of participation in the implementation of each function (weight indicator) for the elements involved in the implementation of several functions. The subsequent transfer of costs from the elements to the functions assigned to them is carried out based on the "element - function" correspondence matrix. The authors then determined the cost share of each feature based on the costs of the individual items in the product. Based on the identified costs of individual functions, the authors determined which elements should be given the most attention and, in particular, which potential design errors can be avoided, and where the greatest savings can be achieved if costs are optimized.

A particular difficulty in determining product cost is the "soft" properties associated with the brand and the prestige of the product or other feelings that consumers may experience when applying it. In addition, they can also be associated with some design, novelty, etc. All of these sources are intangible for any function that reflects these properties. This makes such 
functions impossible or nearly impossible to evaluate. The VE working group evaluates and sets the cost for these functions depending on their contribution to the value of the product.

The crucial functions of the research object are the core functions, because they reflect the purpose of the object, while the ensuring and managing functions play an important role in the operation of the system as a whole. In order to objectively determine the significance of the forklift core functions, a survey was conducted of three experts: a representative of the manufacturer design department, a representative of the consumer organization and a representative of the service providing maintenance and repair services for forklifts.

The function significance is a characteristic that reflects the function role of a lower level of a functional model in the function implementation of a higher level. The significance is established by expert judgment and for the core functions reflects the influence of the function on the performance of the core function of the object. As a result, the authors of the article accordingly formed three versions for the distribution of the core functions significance, which are presented in Table 1.

Table 1. Versions for the distribution of significance between the core functions.

\begin{tabular}{|l|c|c|c|}
\hline \multicolumn{3}{|c|}{$\begin{array}{c}\text { Chief function - Ensure transportation and placement on racks up to } \mathbf{6} \text { m high of cargo } \\
\text { weighing up to 2 tons. }\end{array}$} \\
\cline { 2 - 4 } Core functions & $\begin{array}{c}\text { Fersionction significance, share } \\
\mathbf{1}\end{array}$ & $\begin{array}{c}\text { Version } \\
\mathbf{2}\end{array}$ & $\begin{array}{c}\text { Version } \\
\mathbf{3}\end{array}$ \\
\hline $\begin{array}{l}\text { 1. Carry out transportation of cargo weighing up to } \\
\text { 2 tons }\end{array}$ & $\mathbf{0 , 2 5}$ & $\mathbf{0 , 3}$ & $\mathbf{0 , 3 3}$ \\
\hline $\begin{array}{l}\text { 1.1. Move forward / backward with a maximum speed } \\
\text { of 14 km/h, ensuring passability in warehouse openings } \\
\text { up to 2800 mm high }\end{array}$ & 0,1 & 0,12 & 0,135 \\
\hline 1.2. Carry out breaking & 0,05 & 0,06 & 0,06 \\
\hline 1.3. Maneuver and turn with a radius of 2100 mm & 0,1 & 0,12 & 0,135 \\
\hline 2. Lift 2 tons cargo weighing up to 6 meters & $\mathbf{0 , 2 5}$ & $\mathbf{0 , 4 5}$ & $\mathbf{0 , 3 4}$ \\
\hline $\begin{array}{l}\text { 2.1. Carry out lifting / lowering of the load within the } \\
\text { level of free lift to a height of up to 1720 mm }\end{array}$ & 0,15 & 0,2 & 0,17 \\
\hline $\begin{array}{l}\text { 2.2. Carry out lifting / lowering of a load above the level } \\
\text { of free lift to a height of up to 6000 mm }\end{array}$ & 0,2 & 0,25 & 0,17 \\
\hline 3. Position and place 2 tons at the storage place & $\mathbf{0 , 4}$ & $\mathbf{0 , 2 5}$ & $\mathbf{0 , 3 3}$ \\
\hline 3.1. Carry out the placement of cargo & 0,25 & 0,15 & 0,165 \\
\hline 3.2. Positioning cargo & 0,15 & 0,1 & 0,165 \\
\hline In total & $\mathbf{1}$ & $\mathbf{1}$ & $\mathbf{1}$ \\
\hline
\end{tabular}

Further, the authors constructed three functional-cost diagrams for each of the three versions (figure 3). After that, the degree of discrepancy between the functions significance and the costs amount for their implementation was established.

In the process of analyzing the functional-cost diagram in order to select functions for indepth analysis, 3 options for the correspondence of the significance and cost indicators are considered:

- the significance of the function corresponds to the cost (there is no mismatch);

- the significance of the function exceeds the costs (inconsistency towards significance);

- $\quad$ costs exceed the significance of the function (inconsistency towards costs). 


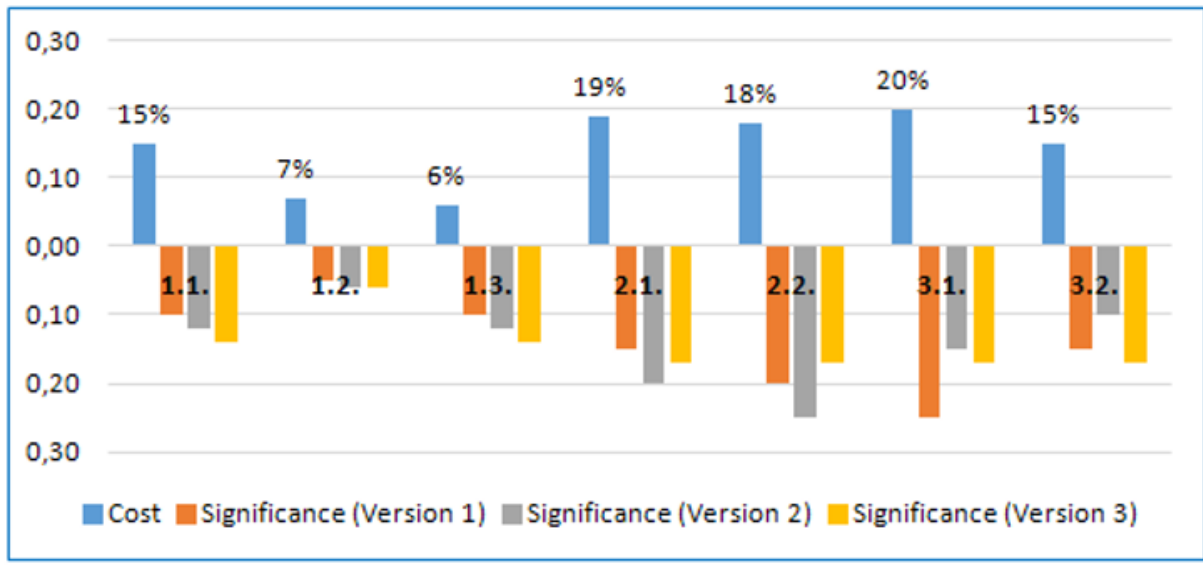

Fig. 3. Functional cost diagram for the product "Electric forklift"

Taking into account the results obtained, the following functions were adopted for further analysis:

* core function 1.1 "Carry out forward / reverse movement at a maximum speed of 14 $\mathrm{km} / \mathrm{h}$, ensuring passability in warehouse openings up to $2800 \mathrm{~mm}$ high." Areas of in-depth analysis: search for reserves to reduce costs; opportunities for cooperation; refusal of a function (product reengineering);

* core function 2.2 "Carry out lifting / lowering of the load above the level of free lift to a height of up to $6000 \mathrm{~mm}$ ". Is a representative of the main function 2 "To lift a load weighing 2 tons to a height of $6 \mathrm{~m}$." Areas of in-depth analysis: the level of design solutions; verification for full compliance with best practices (analogs) and consumer requirements; risk assessment of underestimated costs;

* core function 3.1 "Place the cargo". Areas of in-depth analysis: reserves for cost reduction; level of design solutions.

It is worth noting that when determining the directions of improvement according to the functional-cost diagram, it is necessary to take into account the application product specifics. This is due to the fact that different product consumers from different market segments will have completely different understandings of functional value and costs. It is the exploitation features and the activity specifics in which the designed product will be applied that have a great impact on the perception of the product. Thus, the Value Engineering method makes it possible to improve the ratio of product characteristics, expressed through functions, to their cost, which provides a qualitative improvement in perceived value.

\section{Discussion}

The dynamism of civil markets is characterized by a constant change in consumer preferences, technologies and the level of competition. Many of the best new product ideas and concepts arise from the challenges consumers face with existing products during their operational phase. Therefore, an important aspect is the need to build constant interaction with consumers of products at the stage of developing a new product [1].

When developing a new product, an enterprise usually faces the problem of forming a demanded product concept and determining a suitable price for this product. It is important to include not only potential customers in the product development process, but also service specialists and all stakeholders. This solution will provide verification of the results at various design stages - from the technical specifications to testing the finished product. The competitiveness of manufactured products requires the application of flexible and complex 
design tools such as the Value Engineering method. The main principle of the VE method is to achieve the most acceptable price-quality ratio for consumers with the lowest or optimal production costs. VE allows you to transform all ideas related to improvement into commercial benefits for the enterprise and its customers.

The approach proposed by the authors to the design of the value of a mechanical engineering product can be used in other subsectors of mechanical engineering, as well as in other industries where the product is a high-tech product. It is important to note that due to the introduction of the VE method, the costs of the enterprise can be greatly reduced due to the fact that it is possible to determine which product functions should be taken into further development and which do not require changes or even should be excluded. Thus, the application of the VE method in the development of new products, and therefore the creation of new value, will allow enterprises to gain a competitive advantage in the market and construct effective innovative activities.

\section{References}

1. A.D. Murukina, O.O. Podoliak Applying of open information sources for the development of new products, Ural University Publishing House, pp. 185-188 (2020)

2. M.T. Fernandes Value Analysis Going into a further dimension Engineering, Technology \& Applied Science Research, 5(2), pp. 781-789, (2015)

3. A. Abdullah, E. Adesta Implementation of functional analysis using value analysis value engineering (VAVE), ARPN J. Eng. Appl. Sc., 10(21), pp. 10072-10076, (2015)

4. Kiran D.R. Total Quality Management: Key Concepts and Case Studies (Butterworth Heineman, Oxford, 2017)

5. M. Leber, M. Bastiča, M. Mavriča, A. Ivanišević Value Analysis as an Integral Part of New Product Development, Procedia Engineering, 69, pp. 90-98, (2014)

6. A. Murukina, L. Tipner, M. Prilytskaya, N. Kalinina Marketing aspect in the 'Value Engineering' in the new products development of machine-building, enterprises IOP Conf. Ser: Mat. Sc. and Eng., 966, 012097, (2020) 